\title{
Is fat the sixth taste primary? Evidence and implications
}

\author{
Russell SJ Keast ${ }^{*}$ and Andrew Costanzo
}

\begin{abstract}
Taste is the chemical sense responsible for the detection of non-volatile chemicals in potential foods. For fat to be considered as one of the taste primaries in humans, certain criteria must be met including class of affective stimuli, receptors specific for the class of stimuli on taste bud cells (TBC), afferent fibres from TBC to taste-processing regions of the brain, perception independent of other taste qualities and downstream physiological effects. The breakdown products of the macronutrients carbohydrates (sugars) and proteins (amino acids) are responsible for the activation of sweet and umami tastes, respectively. Following the same logic, the breakdown products of fat being fatty acids are the likely class of stimuli for fat taste. Indeed, psychophysical studies have confirmed that fatty acids of varying chain length and saturation are orally detectable by humans. The most likely fatty acid receptor candidates located on TBC are CD36 and G protein-coupled receptor 120. Once the receptors are activated by fatty acids, a series of transduction events occurs causing the release of neurotransmitters towards afferent fibres signalling the brain. Whether fatty acids elicit any direct perception independent of other taste qualities is still open to debate with only poorly defined perceptions for fatty acids reported. Others suggest that the fatty acid taste component is at detection threshold only and any perceptions are associated with either aroma or chemesthesis. It has also been established that oral exposure to fat via sham feeding stimulates increases in blood TAG concentrations in humans. Therefore, overall, with the exception of an independent perception, there is consistent emerging evidence that fat is the sixth taste primary. The implications of fatty acid taste go further into health and obesity research, with the gustatory detection of fats and their contributions to energy and fat intake receiving increasing attention. There appears to be a coordinated bodily response to fatty acids throughout the alimentary canal; those who are insensitive orally are also insensitive in the gastrointestinal tract and overconsume fatty food and energy. The likely mechanism linking fatty acid taste insensitivity with overweight and obesity is development of satiety after consumption of fatty foods.
\end{abstract}

Keywords: Fat taste, Fatty acid, Obesity, Taste reception, Chemesthesis

\section{The sense of taste}

The sense of taste presumably evolved to inform us about the nutritious or toxic value of potential foods. The primary organ responsible for the sense of taste is the tongue, which contains the biological machinery (taste receptors) to identify non-volatile chemicals in foods and non-foods we place in our mouth. Once a food enters the mouth, the tongue aids in the manipulation of the food, assisting breakdown and bolus formation before swallowing the food. During this critical

\footnotetext{
* Correspondence: russell.keast@deakin.edu.au

Sensory Science Group, School of Exercise and Nutrition Sciences, Centre for Physical Activity and Nutrition, Deakin University, Burwood, VIC 3125,
} Australia

\section{() Biomed Central}

period of food manipulation, the tongue is sampling chemicals in the food, and when food chemicals activate taste receptors, signals are sent from the taste receptors to processing regions of the brain. The signals are decoded by the brain, and we perceive the taste of the food, which could be one of five distinct qualities: sweet, sour, salty, bitter and umami.

It is perhaps appropriate to classify taste as a nutrienttoxin detection system, with the qualities (sweet, etc.) informing us via an associated hedonic response of suitability to swallow or reject, for example sweet elicited by sugars reflecting carbohydrate, sour elicited by free hydrogen ions $\left(\mathrm{H}^{+}\right)$reflecting excessive acid, umami elicited by glutamate and other amino acids reflecting 
protein content, salt elicited by sodium $\left(\mathrm{Na}^{+}\right)$and other ions reflecting mineral content, and bitter reflecting potential toxins in foods. Excessive bitterness or sourness is aversive and informs that the food in our mouth may cause harm and that the best action is to expectorate, whereas the qualities sweet, umami and salty are all appetitive within a relevant intensity range and inform that the food contains compounds we should ingest, in this case, essential nutrients such as carbohydrate, protein and minerals, respectively. As the taste system has evolved to detect the nutrients or toxins in foods prior to ingestion, it makes sense that fats, an essential energy-dense macronutrient required in limited amounts for energy and nutritional needs, would be detected through taste, as other macronutrients namely carbohydrates and proteins are detected through the tastes of sweet and umami.

\section{Fat taste}

Fat taste is an area of increasing interest particularly in chemosensory and nutrition research with the possibility that it may be linked with dietary consumption of fatty foods. The intake and regulation of dietary fats is considered especially important in the development of overweight and obesity, given their high energy density and palatability alongside their ability to promote excess energy intake. The intake and regulation of fats in the obese state appears especially problematic given that obese persons prefer higher fat foods that represent significant portions of the obese diet.

Fat has been classified as a taste as early as $330 \mathrm{BC}$ by Aristotle and many other academics over the centuries [1]. More recently, fat has been associated with texture, flavour release and thermal properties in foods, but not the sense of taste [2]. This may seem like an irrelevant academic point, but the taste system is only activated when a saliva-soluble component of a potential food activates receptors on taste cells. Adding to the importance of the sense of taste is the interplay between taste cell activation and multiple digestive processes, therefore making the link between taste and fat intake very important, especially given the link dietary fat has with the development of obesity.

For fat to be generally accepted as a taste, it must meet five criteria: 1) There must be a distinct class of affective stimuli, and the stimuli responsible for fat taste are the breakdown products of fats and fatty acids [3,4]. 2) There should be transduction mechanisms including receptors to change the chemical code of the stimuli to electrical signal. Emerging evidence suggests that CD36 and G protein-coupled receptor (GPCR) 120 are the most likely candidate receptors on taste bud cells (TBC), with multiple taste transduction mechanisms also involved [5]. 3) There must be neurotransmission of the electrical signal to processing regions of the brain [6,7]. 4) There should be perceptual independence from other taste qualities. This criterion is controversial, and while there is certainly no obvious perception such as the sweetness of sucrose or saltiness of $\mathrm{NaCl}$, some researchers claim less well-defined perceptions for fatty acids [8]. Others suggest that the fatty acid taste component is at detection threshold only and any definable perceptions are associated with either aroma or chemesthesis [4,9]. 5) Finally, there must be physiological effects after activation of taste bud cells.

What follows is a brief summary of evidence supporting fat as the sixth taste and potential relevance of fat taste sensitivity to food consumption and development of obesity.

\section{Fatty acids as stimuli}

While it is well established that oxidised or reverted fatty acids or fatty acids at high concentrations are unpleasant to taste, the taste quality of fatty acids will vary according to their concentration in a food. The levels of fatty acids involved in fat taste are low enough not to be considered unpleasant in unspoiled food, yet sufficient to activate putative oral receptors. For example, the concentrations of fatty acids required for detection are within ranges which may be inherently present in edible fresh and processed foods $(0.1 \%-3 \% w / v)$ [10], or perhaps made available through enzymatic hydrolysis by lingual lipase.

\section{Lingual lipase}

Lipase enzymes are very important as they break the triacylglycerols (TAGs) down so that free fatty acids can be transduced by cellular pathways. In humans, however, lingual lipase presence remains controversial. Data has suggested that lipolytic activity may be present in humans $[9,11]$, although it is unknown whether sufficient concentrations of lingual lipase are produced and whether this originates from endogenous sources or oral microbes. The presence of lipase does appear to have an influence on fatty acid thresholds with research showing that the addition of orlistat (lipase inhibitor) during testing increased fatty acid thresholds [12]. Overall, the weight of evidence suggests that free fatty acids in fatty foods will be in sufficient concentrations to activate putative receptors on taste cells.

\section{Fatty acid taste receptors and transduction CD36 transporter}

One of the proposed mechanisms of oral fatty acid nutrient detection is via CD36, a fatty acid transporter [13]. CD36 is found in the oral cavity on human taste buds, specifically the circumvallate and foliate papillae [14]. Genetic variants of CD36 have been associated with 
variation of oleic acid (C18:1) detection threshold [12], providing further evidence for a role of CD36 for fat taste in humans.

\section{G protein-coupled receptors}

It has been proposed that CD36 may work together with other possible receptors like GPCRs in a signalling cascade to detect fatty acids [8]. GPCR120 (and possibly GPCR40) are activated by fatty acids initiating peripheral signalling cascade that includes a release of calcium that activates the cation channel transient receptor potential channel type M5 (TRPM5) [15]. GPCR120 has been expressed in the apical portion of types I and II cells from animal taste buds [16,17] and, more recently, human taste buds [8].

\section{Delayed rectifying potassium channels}

Delayed rectifying potassium (DRK) channels are known to be implicated in the transduction pathway of a variety of taste stimuli. A study by Gilbertson found that polyunsaturated fatty acids (PUFA) slow down DRK polarisation on the foliate and circumvallate papillae taste cells and therefore allow fat to be detected [18].

\section{Neurotransmitter release}

A transduction mechanism that converts the chemical signal to an electrical signal is required to establish the taste component in dietary fat consumption. Previous studies suggested that the general chemoreception pathway starts from the fatty acids triggering the receptor or ion channel and results in the complex cascade that leads to the cell depolarization. The neurotransmitters such as noradrenaline and serotonin (5-hydroxytryptamine (5-HT)) will then be secreted towards afferent nerve fibres which trigger the orosensory perception [19]. Further research is required relating specifically to neurotransmission of fat taste.

\section{Perceptual independence}

For all tastants, perception of the taste runs along a sensory concentration continuum (Figure 1). At very low concentrations, fatty acids may be detected, albeit with no taste quality attached, i.e. the concentration is too low to be recognised as a taste [20]. As the concentration increases, e.g. as a result of fat hydrolysis within a food, fatty acids may then be tasted or recognised. Once the concentration of fatty acids is high enough for recognition and supra-threshold, the flavour is generally unpleasant. At the supra-threshold level, it is likely that

Detection, recognition and terminal thresholds of tastants.

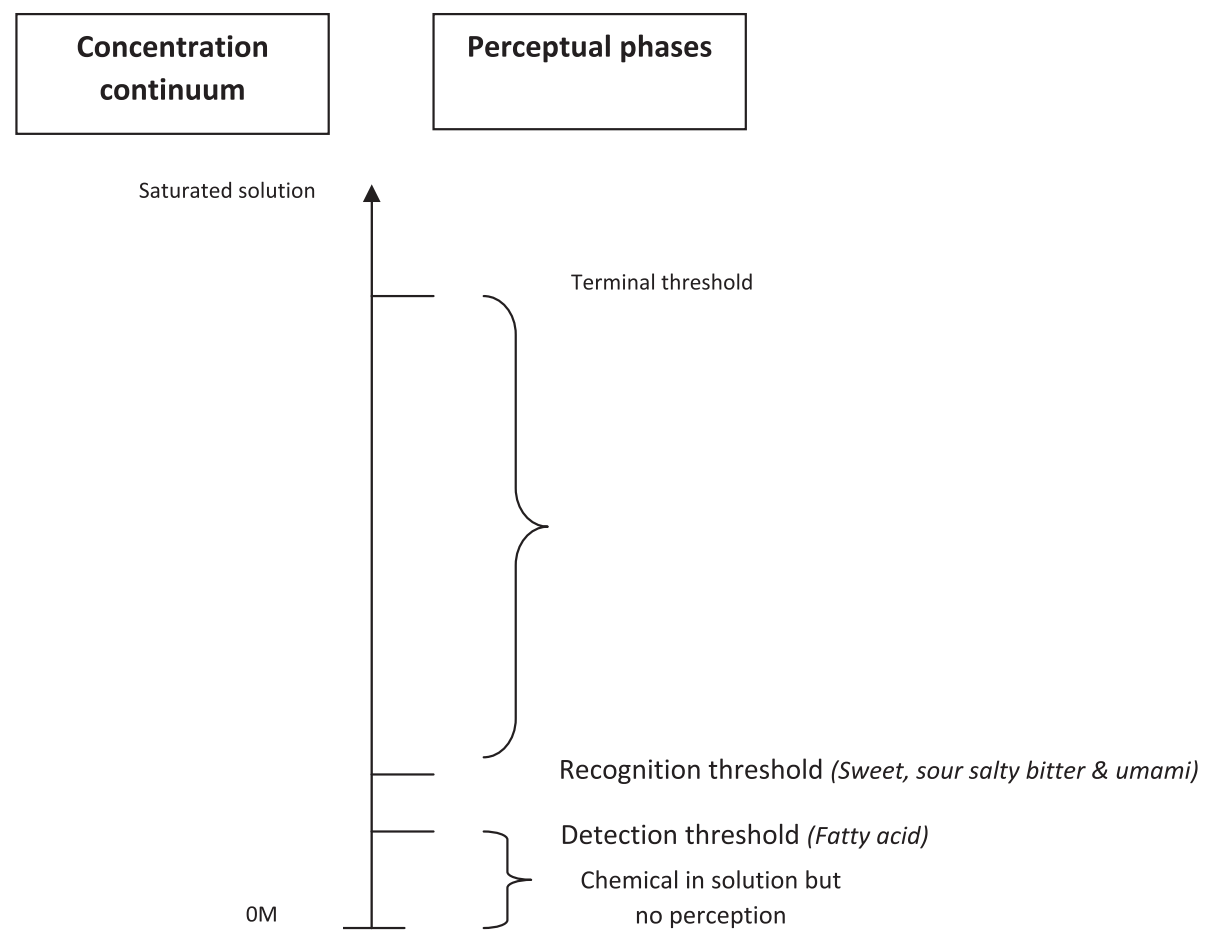

Figure 1 Relationship between chemical concentration, detection threshold and recognition threshold. The left-hand side represents chemical concentration from $0 \mathrm{M}$ solution to a saturated solution. The right-hand side represents the perceptual relationship to increasing concentration and where fatty acid detection is placed in comparison to the five basic tastes. 
sensory systems other than taste are involved, for example smell or chemesthesis. Whether there is a recognisable taste quality associated with fat is still up for debate, but there is no doubt that a fat taste quality is not equivalent to easily identified qualities such as sweet or salty. One taste dimension for fatty acids that is reliably measurable is detection threshold, and research has shown that this measure is independent of detection thresholds for other basic tastes, thereby meeting the criteria for perceptual independence [4].

\section{Physiological responses to oral fatty acid exposure}

In humans, a 2.8-fold increase in plasma TAG concentrations was recorded in response to oral fat loads. These effects are not observed with sensory-matched fat mimetics, textural cues or smell [21,22], supporting the view that fatty acids activate putative taste receptors that generate an immediate signal which is transmitted to other parts of the periphery, preparing the body for fat digestion and absorption. Additional investigations have also reported fat-specific cephalic phase responses following oral stimulation with fats that include increases in lipase secretion [23]; transient stimulation of gastrointestinal hormones, including cholecystokinin (CCK), pancreatic polypeptide (PP) and peptide YY (PYY) [24,25]; as well as variations in postprandial glucose and insulin $[24,26]$.

\section{Relevance of fat taste to development of obesity}

In rodents, differences in fat taste sensitivity appear to influence fat preference, consumption and predisposition to obesity, hinting at a novel role of the taste system in the control of both food intake and weight regulation [27-29]. It has been established that different rodent strains are selectively more or less sensitive to fatty acids and that differences in fat taste are inherently linked to dietary intake and preference.

For example, when wild-type mice were compared to GPCR120 and GPCR40 knock-out mice, the knock-out mice showed an attenuated preference for linoleic acid (C18:2) and C18:1, suggesting that GPCR120 and GPCR40 play a role in the perception of fatty acids [16]. Furthermore, when GPCR120-deficient mice were fed a high-fat diet, they developed obesity and other side effects of metabolic syndrome, indicating a role in regulation of energy intake [30]. Moreover, a high-fat diet reduced expression of CD36 in obese rats which may be associated with fat taste adaptation and also indicates a role in regulation of energy intake [31]. There is also the possibility that CD36 may be involved with the onset of fat-induced satiety [32]. Animal studies have strongly suggested a link between oral sensitivity to fatty acids and development of obesity, with those animals less sensitive to fatty acids unable to adequately regulate intake and overconsuming energy. In other words, the more you taste fat, the less fat you eat.
A feature of the taste system is the large individual differences in sensitivity to compounds [33]. Differential dietary practices amongst obese and lean individuals, especially with regard to fat consumption and preference, are also well established, for example obese individuals have shown a preference for high-fat foods and prefer a greater concentration of fat within specific food matrices when compared to lean individuals $[34,35]$. Such variations in the taste system along with dietary intake and behaviours have been the focus of recent research studies.

The relationship between oral fatty acid sensitivity, dietary fat intake and body mass index (BMI) has recently been investigated by our group and others [9,36-40]. In general, it was found that those who were more sensitive to the fatty acid C18:1 had lower energy intakes and consumed less total dietary fats and were also better at detecting the fat content of food (custard) [9,37,38]. Another study by Stewart et al. extended these results and also found a relationship in humans between fatty acid sensitivity, food consumption and dietary behaviours, whereby those who were hyposensitive consumed more high-fat dairy products, high-fat spreads and fatty red meat [38]. Conversely, hypersensitive individuals reported behaviours including trimming the fat off meat and avoiding saturated fats [38]. Additionally, various human studies have reported that participants who were classified as hypersensitive to fatty acids also had lower BMIs than hyposensitive individuals $[9,38,39,41]$; however, other studies have failed to find such associations [37,42]. It has also been reported that fatty acid sensitivity can be modulated by dietary fat, with a high-fat diet causing attenuation of fat taste thresholds in lean individuals, while a low-fat diet results in increased sensitivity to fatty acids [37]. Keller et al. has suggested a possible association between polymorphisms in the CD36 receptor, oral fat perception and fat preference in human subjects [43]. Changes in the preference of high-fat foods have been observed following 12- to 24week dietary interventions involving fat-restriction, which leads to a decrease in the pleasantness, taste and preference of high-fat foods, suggesting that the experience of fats in foods can be modulated by the diet [44].

The association between fat taste and obesity is probably a result of a coordinated alimentary canal response to dietary fat $[45,46]$ (Figure 2). Indeed, a link between oral fatty acid chemoreception and gastrointestinal tract (GIT) responses to fatty acid has been established with obese individuals having impaired responses to fatty acid in the oral cavity and the GIT $[12,37,41,47,48]$ compared to healthy-weight subjects. The presence of fats in the small intestine in healthy, normal-weight subjects generates potent satiety signals [46]. Gastric emptying is slowed, gut hormones CCK and PYY are released, and ghrelin is inhibited [49,50], altogether causing suppression of energy intake. These physiological satiety 


\section{Comparison of satiety feedback after fatty acid chemoreception in lean and obese individuals.}

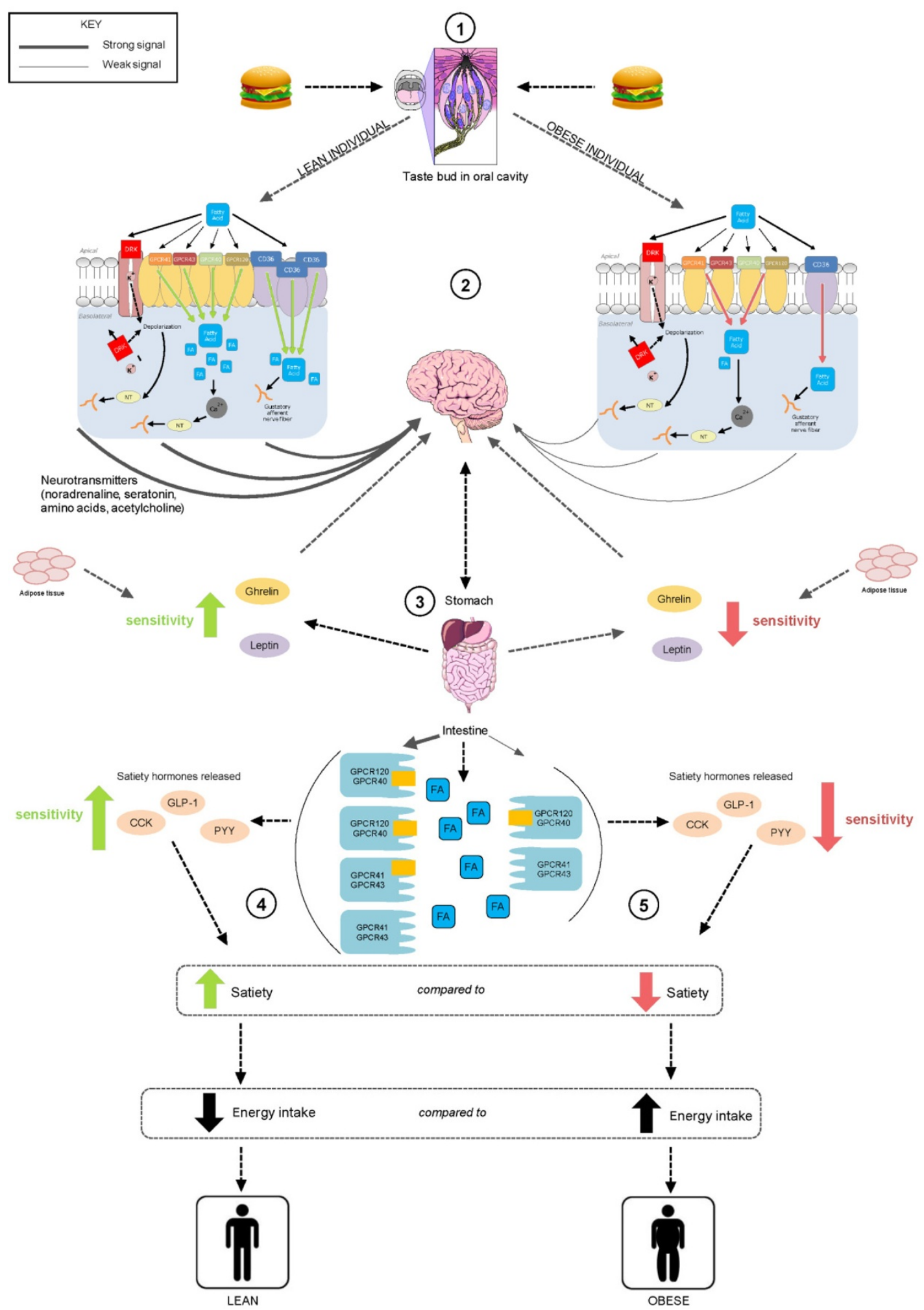

Figure $\mathbf{2}$ (See legend on next page.) 
(See figure on previous page.)

Figure 2 Schematic representation of fatty acid chemoreception in the oral cavity and gastrointestinal tract (alimentary canal) in lean (left) and obese (right) individuals. (1) Fat is present in foods in the form of TAG; free fatty acids are generated during the breakdown of fats and by lipase enzymes in the oral cavity. (2) Fatty acids access putative receptors (CD36, GPCR40, GPCR41, GPCR43, GPCR120 and delayed rectifying potassium (DRK) channels) within taste cells; lean individuals have greater quantities of these receptors compared to obese individuals. The receptors elicit the release of intracellular $\mathrm{Ca}^{2+}$ that in turn activates neurotransmitters and hormones associated with the cephalic response. (3) Following fat ingestion, gastric and pancreatic lipase plays a further role in the hydrolysis of fats enabling access to fatty acid receptors on enteroendocrine cells, stimulating satiety hormones and uptake of fatty acids. As a consequence, sensitivity to ghrelin, which is responsible for hunger stimulation, is inhibited, while the satiety-inducing hormone leptin is released as are the hormones CCK, PYY and GLP-1. (4) In a lean individual, expression of fatty acid receptors is greater, therefore increasing fat sensing ability through the alimentary canal and thereby decreasing energy intake. (5) In comparison, obese individuals have decreased expression of fatty acid receptors, attenuating fat sensing ability and increasing energy intake. Reproduced from [52].

mechanisms may be impaired in the obese with subjects voluntarily consuming twice as much energy from fat products as non-obese [41,51]. A recent study illustrated the link between fatty acid sensitivity, fat consumption and satiety. When the population was stratified according to fat taste sensitivity, those who were classified as orally hyposensitive to $\mathrm{C} 18: 1$ found fat the least satiating macronutrient, while those who were classified as hypersensitive to C18:1 found fat the most satiating. This result was specific for the high-fat meal; this was not observed following a high-carbohydrate, high-protein or balanced meal [36].

\section{Summary}

The existence of a sixth taste elicited by the digestive products of fat (fatty acids) is yet to be confirmed; however, a growing body of evidence from humans and other animal species provides support for this proposition. In support for a functional significance of fat taste, differences in taste sensitivity for fat appear to predict certain dietary behaviours, i.e. decreased sensitivity to fat taste is associated with an increased consumption of fat, and this has been reported in both animal and human studies. Moreover, sensitivity to fat can be modulated by the diet, i.e. consumption of a high-fat diet appears to maximise the body's capacity for fat absorption, with no changes in appetite, suggesting that such changes may accompany or encourage excess fat intake and obesity. These data propose a direct role of the taste system in the consumption and preference of high-fat foods, which may be linked to the development of obesity given that differences in BMI have also been linked to oral fatty acid sensitivity. The mechanism allowing for increased consumption of fat is proposed to be via satiety or fullness signals, as associations in both taste and digestive responses to fat have been reported. The next 5 to 10 years should reveal, conclusively, whether fat can be classified as the sixth taste, but no matter what, there appears to be a functional significance to oral chemosensing of fats.

\section{Abbreviations}

GPCR: G protein-coupled receptor; TBC: Taste bud cell; TAG: Triacylglycerol; DRK: Delayed rectifying potassium; PUFA: Polyunsaturated fatty acids; CCK: Cholecystokinin; PP: Pancreatic polypeptide; PYY: Peptide YY; GIT: Gastrointestinal tract.

\section{Competing interests}

The authors declare that they have no competing interests.

\section{Authors' contributions}

RSJK conceived of the article and drafted the manuscript. AC helped draft the manuscript and revised it for publication. Both authors read and approved the final manuscript.

\section{Acknowledgements}

RSJK is funded by the National Health and Medical Research Council in Australia (Grant 1043780) and Horticulture Australia Limited (BS12006).

Received: 2 December 2014 Accepted: 2 December 2014 Published: 3 February 2015

\section{References}

1. Aristotle: De Anima. $350 \mathrm{BC}$

2. Fennema O: Food Chemistry. 4th edition. Edited by Srinivasan D, Parkin KL, Fennema OR. Boca Raton: CRC; 2007.

3. Chale-Rush A, Burgess JR, Mattes RD: Evidence for human orosensory (taste?) sensitivity to free fatty acids. Chem Senses 2007, 32(5):423-431.

4. Newman L, Keast R: The test retest reliability of fatty acid taste threshold. Chemosens Percept 2013, 6(2):70-77.

5. Gilbertson TA, Khan NA: Cell signaling mechanisms of oro-gustatory detection of dietary fat: advances and challenges. Prog Lipid Res 2014, 53:82-92.

6. Rolls ET, Critchley HD, Browning AS, Hernandi I, Lenard L: Responses to the sensory properties of fat of neurons in the primate orbitofrontal cortex. J Neurosci 1999, 19(4):1532-1540.

7. De Araujo IE, Rolls ET: Representation in the human brain of food texture and oral fat. J Neurosci 2004, 24(12):3086-3093.

8. Galindo MM, Voigt N, Stein J, van Lengerich J, Raguse JD, Hofmann T, Meyerhof W, Behrens M: G protein-coupled receptors in human fat taste perception. Chem Senses 2012, 37(2):123-139.

9. Stewart JE, Feinle-Bisset C, Golding M, Delahunty C, Clifton PM, Keast RS: Oral sensitivity to fatty acids, food consumption and BMI in human subjects. Brit J Nutr 2010, 104(1):145-152.

10. Che Man $Y$, Moh M, van der Voort F: Determination of free fatty acids in crude palm oil and refined-bleached-deodorised palm olein using Fourier transform infrared spectroscopy. J Am Oil Chem Soc 1999, 76:485-490.

11. Kulkarni BV, Mattes RD: Lingual lipase activity in the orosensory detection of fat in humans. Am J Physiol Regul Integr Comp Physiol 2014, 306(12):R879-R885.

12. Pepino MY, Love-Gregory L, Klein S, Abumrad NA: The fatty acid translocase gene CD36 and lingual lipase influence oral sensitivity to fat in obese subjects. J Lipid Res 2012, 53(3):561-566.

13. Abumrad N: CD36 may determine our desire for dietary fats. $J$ Clin Invest 2005, 115(11):2955-2967. 
14. Simons PJ, Kummer JA, Luiken JJ, Boon L: Apical CD36 immunolocalization in human and porcine taste buds from circumvallate and foliate papillae. Acta Histochem 2011, 113(8):839-843.

15. Liu P, Shah BP, Croasdell S, Gilbertson TA: Transient receptor potential channel type M5 is essential for fat taste. J Neurosci 2011, 31(23):8634-8642.

16. Cartoni C, Yasumatsu K, Ohkuri T, Shigemura N, Yoshida R, Godinot N, le Coutre J, Ninomiya Y, Damak S: Taste preference for fatty acids is mediated by GPR40 and GPR120. J Neurosci 2010, 30(25):8376-8382.

17. Matsumura S, Mizushige T, Yoneda T, Iwanaga T, Tsuzuki S, Inoue K, Fushiki T: GPR expression in the rat taste bud relating to fatty acid sensing. Biomed Res 2007, 28(1):49-55.

18. Gilbertson TA: Gustatory mechanisms for the detection of fat. Curr Opin Neurobiol 1998, 8(4):447-452.

19. Dando R, Roper SD: Cell-to-cell communication in intact taste buds through ATP signalling from pannexin 1 gap junction hemichannels. J Physiol 2009, 587(24):5899-5906.

20. Keast $\mathrm{R}$, Roper J: A complex relationship among chemical concentration, detection threshold, and suprathreshold intensity of bitter compounds. Chem Senses 2007, 32(3):245-253.

21. Mattes RD: The taste of fat elevates postprandial triacylglycerol. Physiol Behav 2001, 74(3):343-348

22. Mattes RD: Oral exposure to butter, but not fat replacers elevates postprandial triacylglycerol concentration in humans. J Nutr 2001, 131(5):1491-1496

23. Wøjdemann M, Olsen O, Nørregaard P, Sternby B, Rehfeld JF: Gastric lipase secretion after sham feeding and cholinergic blockade. Dig Dis Sci 1997, 42(5):1070-1075.

24. Robertson MD, Jackson KG, Williams CM, Fielding BA, Frayn KN: Prolonged effects of modified sham feeding on energy substrate mobilization. Am J Clin Nutr 2001, 73(1):111-117.

25. Wisén O, Björvell H, Cantor $P$, Johansson C, Theodorsson E: Plasma concentrations of regulatory peptides in obesity following modified sham feeding (MSF) and a liquid test meal. Regul Pept 1992, 39(1):43-54.

26. Chavez-Jauregui RN, Mattes RD, Parks EJ: Dynamics of fat absorption and effect of sham feeding on postprandial lipema. Gastroenterology 2010, 139(5):1538-1548.

27. Takeda M, Imaizumi M, Fushiki T: Preference for vegetable oils in the two-bottle choice test in mice. Life Sci 2000, 67(2):197-204.

28. Takeda M, Sawano S, Imaizumi M, Fushiki T: Preference for corn oil in olfactory-blocked mice in the conditioned place preference test and the two-bottle choice test. Life Sci 2001, 69(7):847-854

29. Verhagen JV, Rolls ET, Kadohisa M: Neurons in the primate orbitofrontal cortex respond to fat texture independently of viscosity. I Neurophysiol 2003, 90(3):1514-1525

30. Ichimura A, Hirasawa A, Poulain-Godefroy O, Bonnefond A, Hara T, Yengo L, Kimura I, Leloire A, Liu N, lida K, Choquet H, Besnard P, Lecoeur C, Vivequin S, Ayukawa K, Takeuchi M, Ozawa K, Tauber M, Maffeis C, Morandi A, Buzzetti R, Elliott P, Pouta A, Jarvelin MR, Körner A, Kiess W, Pigeyre M, Caiazzo R, Van Hul W, Van Gaal L, et al: Dysfunction of lipid sensor GPR120 leads to obesity in both mouse and human. Nature 2012, 483(7389):350-354.

31. Zhang XJ, Zhou LH, Ban X, Liu DX, Jiang W, Liu XM: Decreased expression of CD36 in circumvallate taste buds of high-fat diet induced obese rats. Acta Histochem 2011, 113(6):663-667.

32. Naville D, Duchampt A, Vigier M, Oursel D, Lessire R, Poirier H, Niot I, Bégeot M, Besnard P, Mithieux G: Link between intestinal CD36 ligand binding and satiety induced by a high protein diet in mice. PLoS One 2012, 7(1):e30686.

33. Keast RSJ, Dalton P, Breslin PAS: Flavour interactions at the sensory level. In Flavour Perception. Edited by Taylor A. Oxford: Blackwell; 2004:228-255.

34. Bray GA, Paeratakul S, Popkin BM: Dietary fat and obesity: a review of animal, clinical and epidemiological studies. Physiol Behav 2004, 83(4):549-555

35. Rissanen A, Hakala P, Lissner L, Mattlar CE, Koskenvuo M, Rönnemaa T: Acquired preference especially for dietary fat and obesity: a study of weight-discordant monozygotic twin pairs. Int J Obes Relat Metab Disord 2002, 26(7):973-977.

36. Keast RS, Azzopardi KM, Newman LP, Haryono RY: Impaired oral fatty acid chemoreception is associated with acute excess energy consumption. Appetite 2014, 80C:1-6.

37. Stewart J, Keast RS: Recent fat intake modulates fat taste sensitivity in lean and overweight subjects. Int J Obesity 2012, 36:834-842.
38. Stewart J, Newman LP, Keast RS: Oral sensitivity to oleic acid is associated with fat intake and body mass index. Clin Nutr 2011, 30:838-844.

39. Martínez-Ruiz NR, López-Díaz JA, Wall-Medrano A, Jiménez-Castro JA, Angulo O: Oral fat perception is related with body mass index, preference and consumption of high-fat foods. Physiol Behav 2014, 129:36-42.

40. Tucker RM, Edlinger C, Craig BA, Mattes RD: Associations between BMI and fat taste sensitivity in humans. Chem Senses 2014, 39(4):349-357.

41. Stewart JE, Seimon RV, Otto B, Keast RS, Clifton PM, Feinle-Bisset C: Marked differences in gustatory and gastrointestinal sensitivity to oleic acid between lean and obese men. Am J Clin Nutr 2011, 93:703-711.

42. Running CA, Mattes RD, Tucker RM: Fat taste in humans: sources of within- and between-subject variability. Prog Lipid Res 2013, 52(4):438-445

43. Keller KL, Liang LC, Sakimura J, May D, van Belle C, Breen C, Driggin E, Tepper BJ, Lanzano PC, Deng L, Chung WK: Common variants in the CD36 gene are associated with oral fat perception, fat preferences, and obesity in African Americans. Obesity (Silver Spring) 2012, 20(5):1066-1073.

44. Mattes RD: Fat preference and adherence to a reduced-fat diet. Am J Clin Nutr 1993, 57(3):373-381.

45. Mattes RD: Fat taste and lipid metabolism in humans. Physiol Behav 2005, 86(5):691-697.

46. Stewart J, Feinle-Bisset C, Keast RS: Fatty acid detection during food consumption and digestion: associations with ingestive behavior and obesity. Prog Lipid Res 2011, 50(3):225-233.

47. Samra RA: Fats and satiety. In Fat Detection: Taste, Texture, and Post Ingestive Effects. Edited by Montmayeur JP, le Coutre J. Boca Raton: CRC; 2010.

48. Brennan IM, Luscombe-Marsh ND, Seimon RV, Otto B, Horowitz M, Wishart JM, Feinle-Bisset C: Effects of fat, protein, and carbohydrate and protein load on appetite, plasma cholecystokinin, peptide YY, and ghrelin, and energy intake in lean and obese men. Am J Physiol Gastrointest Liver Physiol 2012, 303(1):G129-G140.

49. Blundell J, Macdiarmid J: Fat as a risk factor for overconsumption: satiation, satiety and patterns of eating. J Am Diet Assoc 1997, 97(7):63-69.

50. Feinle C, O'Donovan D, Doran S, Andrews JM, Wishart J, Chapman I, Horowitz M: Effects of fat digestion on appetite, APD motility, and gut hormones in response to duodenal fat infusion in humans. Am J Physiol Gastrointest Liver Physiol 2003, 284(5):G798-G807.

51. Blundell JE, Burley VJ, Cotton JR, Lawton CL: Dietary fat and the control of energy intake: evaluating the effects of fat on meal size and postmeal satiety. Am J Clin Nutr 1993, 57(5):772S-777S. Discussion 777S-778S.

52. Newman L, Haryono R, Keast R: Functionality of fatty acid chemoreception: a potential factor in the development of obesity? Nutrients 2013, 5(4):1287-1300.

doi:10.1186/2044-7248-4-5

Cite this article as: Keast and Costanzo: Is fat the sixth taste primary? Evidence and implications. Flavour 2015 4:5

\section{Submit your next manuscript to BioMed Central and take full advantage of:}

- Convenient online submission

- Thorough peer review

- No space constraints or color figure charges

- Immediate publication on acceptance

- Inclusion in PubMed, CAS, Scopus and Google Scholar

- Research which is freely available for redistribution 